\title{
Carbon-carbon bond cleavage for Cu-mediated aromatic trifluoromethylations and pentafluoroethylations
}

\author{
Tsuyuka Sugiishi ${ }^{1}$, Hideki Amii ${ }^{*}$, Kohsuke Aikawa ${ }^{2}$ and Koichi Mikami ${ }^{* 2}$
}

Review

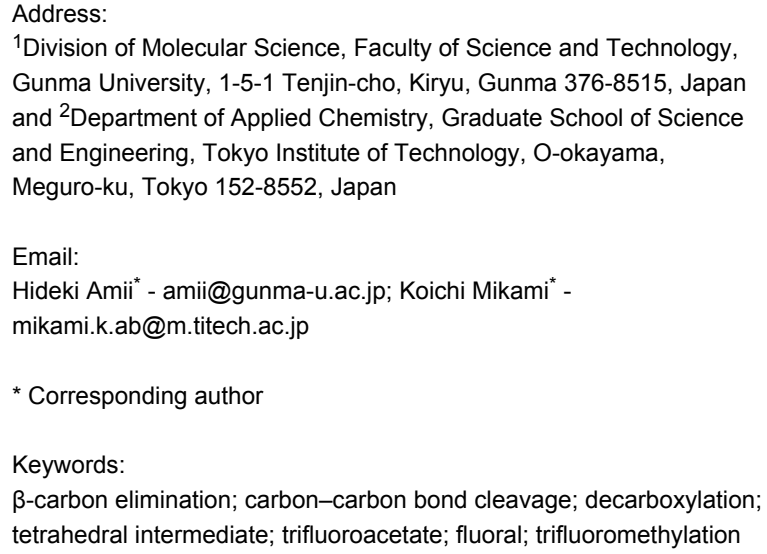

${ }^{1}$ Division of Molecular Science, Faculty of Science and Technology, Gunma University, 1-5-1 Tenjin-cho, Kiryu, Gunma 376-8515, Japan and ${ }^{2}$ Department of Applied Chemistry, Graduate School of Science and Engineering, Tokyo Institute of Technology, O-okayama, Meguro-ku, Tokyo 152-8552, Japan

Email:

Hideki Amii ${ }^{*}$ - amii@gunma-u.ac.jp; Koichi Mikami* -

mikami.k.ab@m.titech.ac.jp

* Corresponding author

Keywords:

$\beta$-carbon elimination; carbon-carbon bond cleavage; decarboxylation; tetrahedral intermediate; trifluoroacetate; fluoral; trifluoromethylation

Beilstein J. Org. Chem. 2015, 11, 2661-2670.

doi:10.3762/bjoc. 11.286

Received: 30 September 2015

Accepted: 11 December 2015

Published: 18 December 2015

This article is part of the Thematic Series "Copper catalysis in organic synthesis".

Guest Editor: S. R. Chemler

(C) 2015 Sugiishi et al; licensee Beilstein-Institut.

License and terms: see end of document.

\begin{abstract}
This short review highlights the copper-mediated fluoroalkylation using perfluoroalkylated carboxylic acid derivatives. Carbon-carbon bond cleavage of perfluoroalkylated carboxylic acid derivatives takes place in fluoroalkylation reactions at high temperature $\left(150-200^{\circ} \mathrm{C}\right)$ or under basic conditions to generate fluoroalkyl anion sources for the formation of fluoroalkylcopper species. The fluoroalkylation reactions, which proceed through decarboxylation or tetrahedral intermediates, are useful protocols for the synthesis of fluoroalkylated aromatics.
\end{abstract}

\section{Introduction}

Organofluorine compounds attract attention because of their applicability in various fields, such as medicine, agrochemical and material science. It has been widely reported that nearly $15 \%$ of pharmaceuticals and $20 \%$ of agrochemicals on the market contain fluorine atoms, including several of the top drugs. Of particular interest are compounds containing the structural motif of a (trifluoromethyl)aryl group $\left(\mathrm{Ar}-\mathrm{CF}_{3}\right)$ [1-7]. The characteristic size, strong electron-withdrawing ability, and the high lipophilicity of the trifluoromethyl group are key properties of biologically active $\mathrm{CF}_{3}$-containing molecules [8]. Perfluoroalkylcopper compounds $\left(\mathrm{C}_{n} \mathrm{~F}_{2 n+1} \mathrm{Cu}\right)$, which are soft and relatively stable perfluoroalkyl organometallic reagents $\left(\mathrm{C}_{n} \mathrm{~F}_{2 n+1} \mathrm{M}\right)$ with high reactivity, act as prominent cross-coupling participants in aromatic perfluoroalkylation reactions [9-32]. In order to prepare $\mathrm{C}_{n} \mathrm{~F}_{2 n+1} \mathrm{Cu}$ species, several representative protocols have been reported. Among these protocols, each method has individual merit. Particularly, Ruppert-Prakash reagents $\left(\mathrm{C}_{n} \mathrm{~F}_{2 n+1} \mathrm{SiR}_{3}\right)$ have been used as the source of perfluoroalkyl 
anions $\left(\mathrm{C}_{n} \mathrm{~F}_{2 n+1}{ }^{-}\right)$for the generation of $\mathrm{C}_{n} \mathrm{~F}_{2 n+1} \mathrm{Cu}$. However, perfluoroalkylsilane sources are costly for large-scale operation. On the other hand, economical and useful perfluoroalkylated carboxylic acid derivatives, such as perfluoroalkylated carboxylates $\left(\mathrm{C}_{n} \mathrm{~F}_{2 n+1} \mathrm{CO}_{2} \mathrm{Na}\right.$ or $\left.\mathrm{C}_{n} \mathrm{~F}_{2 n+1} \mathrm{CO}_{2} \mathrm{~K}\right)$, halodifluoroacetates $\left(\mathrm{XCF}_{2} \mathrm{CO}_{2} \mathrm{R}\right)$, perfluoroalkyl carboxylates $\left(\mathrm{C}_{n} \mathrm{~F}_{2 n+1} \mathrm{CO}_{2} \mathrm{R}\right)$, perfluoroalkyl ketones $\left(\mathrm{C}_{n} \mathrm{~F}_{2 n+1} \mathrm{COR}\right)$, and hemiaminals derived from fluoral $\left(\mathrm{CF}_{3} \mathrm{C}\left(\mathrm{OSiMe}_{3}\right) \mathrm{NR}_{2}\right)$, can generate $\mathrm{C}_{n} \mathrm{~F}_{2 n+1} \mathrm{Cu}$ via carbon-carbon bond cleavage. Herein we focus on $\mathrm{Cu}$-mediated perfluoroalkylation reactions through which carbon dioxide, the esters, or the $N$-formylamines are eliminated from the perfluoroalkyl reagents.

\section{Review}

\section{Decarboxylation of perfluoroalkylacetates}

Trifluoroacetate salts are one of the most readily available trifluoromethylating agents compared to ozone-depleting $\mathrm{CF}_{3} \mathrm{Br}$, and expensive $\mathrm{CF}_{3} \mathrm{I}$. Sodium trifluoroacetate $\left(\mathrm{CF}_{3} \mathrm{CO}_{2} \mathrm{Na}\right)$ is a stable compound at room temperature. Under heating conditions $\left(150-200{ }^{\circ} \mathrm{C}\right), \mathrm{CF}_{3} \mathrm{CO}_{2} \mathrm{Na}$ plays the role of the $\mathrm{CF}_{3}{ }^{-}$ source and $\left[\mathrm{CF}_{3} \mathrm{Cu}\right]$ species with $\mathrm{CuI}$ are generated in situ. In the presence of $\mathrm{CuI}, \mathrm{CF}_{3} \mathrm{CO}_{2} \mathrm{Na}$ undergoes trifluoromethylation with aryl halides via decarboxylation [33,34] (Scheme 1).

A pentafluoroethyl group $\left(\mathrm{C}_{2} \mathrm{~F}_{5}\right)$ was fixed at the arene with sodium pentafluoropropionate [35] (Scheme 2). The reaction mechanism is similar to that of the trifluromethylation using $\mathrm{CF}_{3} \mathrm{CO}_{2} \mathrm{Na}[33,34]$. Upon heating, the mixture of $\mathrm{CF}_{3} \mathrm{CO}_{2} \mathrm{Na}$ and $\mathrm{CuI}$ in NMP, 3-chloroiodobenzene underwent crosscoupling to provide the pentafluoroethylated compound in $80 \%$ yield. The pentafluoroethylated aromatic product was applied to the synthesis of 2,2-difluorostyrenes through $\mathrm{Mg}(0)$-promoted defluorinative silylation followed by fluorine-ion-catalyzed 1,2desilylative defluorination.

Buchwald et al. demonstrated aromatic trifluoromethylation using potassium trifluoroacetate $\left(\mathrm{CF}_{3} \mathrm{CO}_{2} \mathrm{~K}\right), \mathrm{CuI}$ and pyridine under flow conditions. Increasing the reaction temperature from

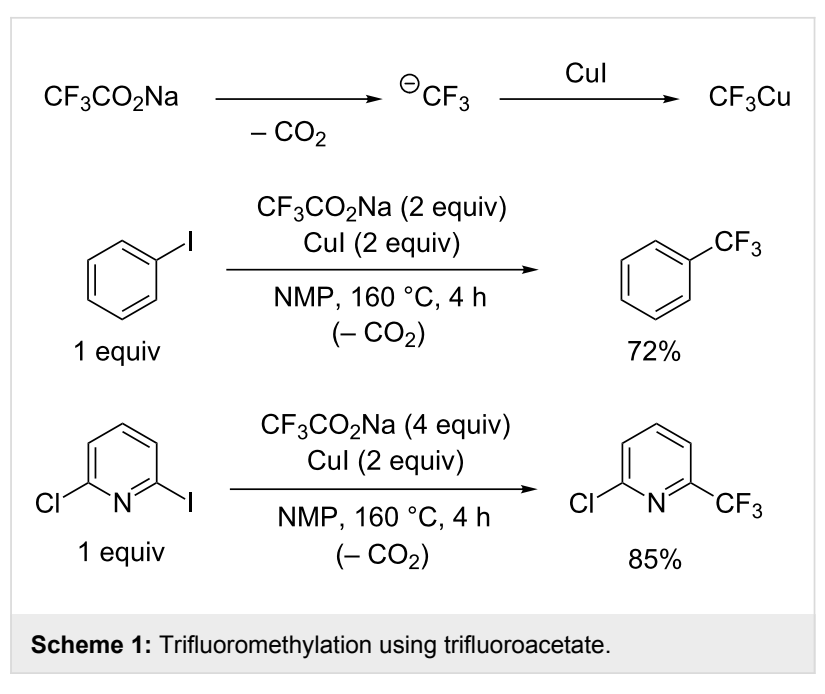

$160{ }^{\circ} \mathrm{C}$ to $200{ }^{\circ} \mathrm{C}$ accelerated the decarboxylation of $\mathrm{CF}_{3} \mathrm{CO}_{2} \mathrm{~K}$ [36] (Scheme 3). The trifluoromethylation using a microreactor resulted in a good yield within a short reaction time by virtue of the thermal stability of $\mathrm{CF}_{3} \mathrm{Cu}$ and control of mixing. Taking advantage of the flow microreactor, a new protocol for scalable aromatic trifluoromethylation was developed.

From a mechanistic aspect, Vicic and co-workers explored the direct generation of $\mathrm{CF}_{3} \mathrm{Cu}$ from $\mathrm{CF}_{3} \mathrm{CO}_{2} \mathrm{Cu}$. The use of (N-heterocyclic carbene)copper-trifluoroacetates prepared from trifluoroacetic acid (TFA) was investigated in the decarboxylative trifluoromethylation of aryl halides [37] (Scheme 4). Not only iodobenzene but also 4-bromotoluene was trifluoromethylated by the $[(\mathrm{NHC}) \mathrm{Cu}(\mathrm{TFA})]$ complex.

The perfluoroalkylation reactions mentioned above require a stoichiometric amount of copper reagent, whereas it was found that the addition of silver salts is effective for the copper-mediated trifluoromethylation of aryl iodides [38] (Scheme 5). The amount of copper used in the reaction was reduced to 30 or $40 \mathrm{~mol} \%$ by adding a small amount of $\mathrm{Ag}_{2} \mathrm{O}$. As a related decarboxylative transformation, silver-mediated aromatic tri-

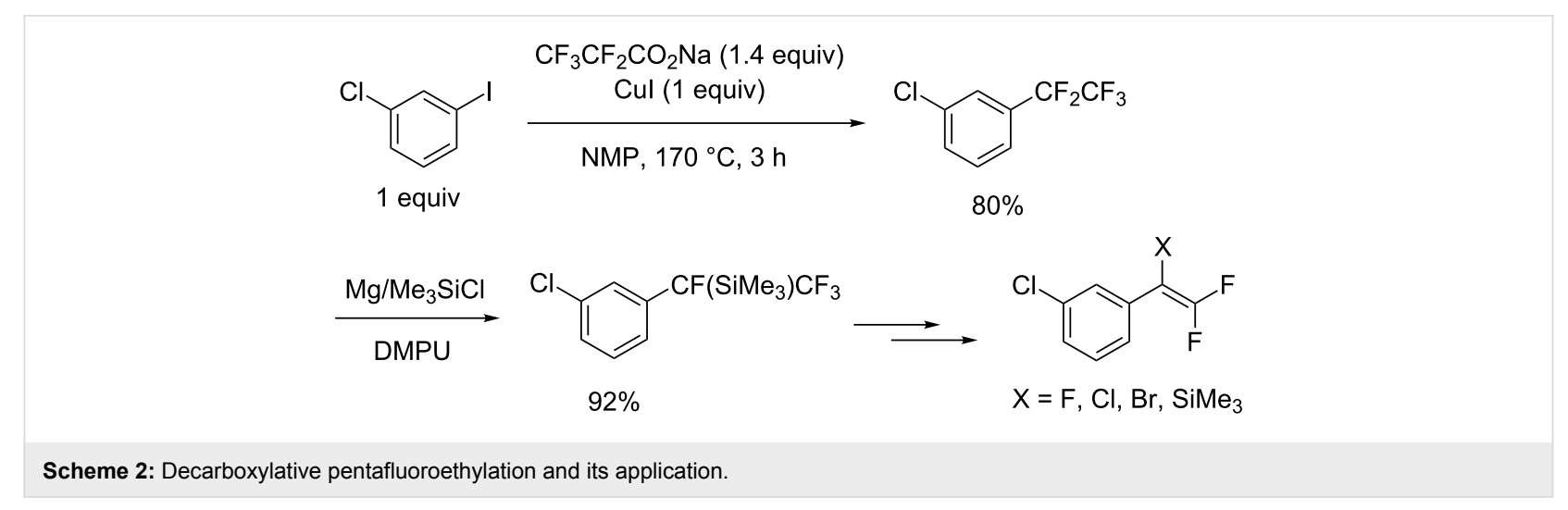




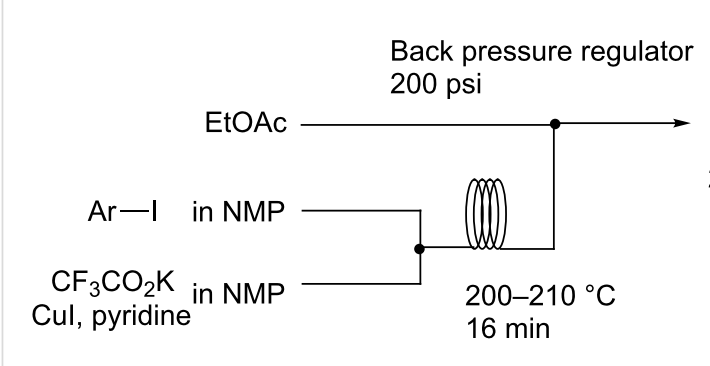

$\mathrm{Ar}-\mathrm{CF}_{3}$

24 examples

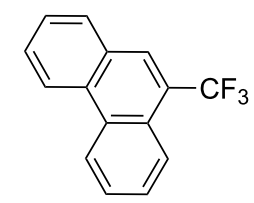

$91 \%$
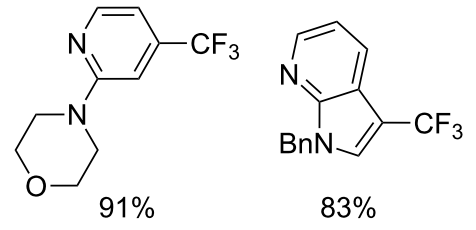

$83 \%$

Scheme 3: Trifluoromethyation with trifluoroacetate in a flow system.

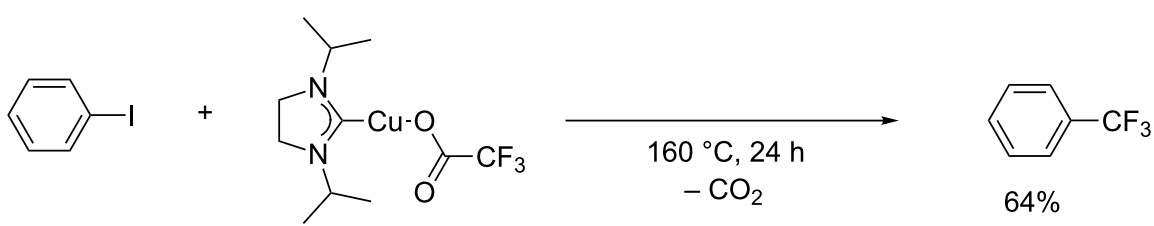

$160^{\circ} \mathrm{C}, 24 \mathrm{~h}$

$-\mathrm{CO}_{2}$

Scheme 4: Trifluoromethylation of 4-bromotoluene by [(NHC)Cu(TFA)].

fluoromethylation was recently developed. Zhang et al. reported the direct aryl $\mathrm{C}-\mathrm{H}$ trifluoromethylation in which TFA works as a trifluoromethylation reagent [39] (Scheme 6). In this reaction, TFA releases a $\mathrm{CF}_{3}$ radical via decarboxylation, which reacts with the arenes to yield trifluoromethyl-substituted products. This report suggests that TFA can act as a trifluoromethyl source in the reaction with inactivated aromatic compounds, while the control of regioselectivity is difficult.
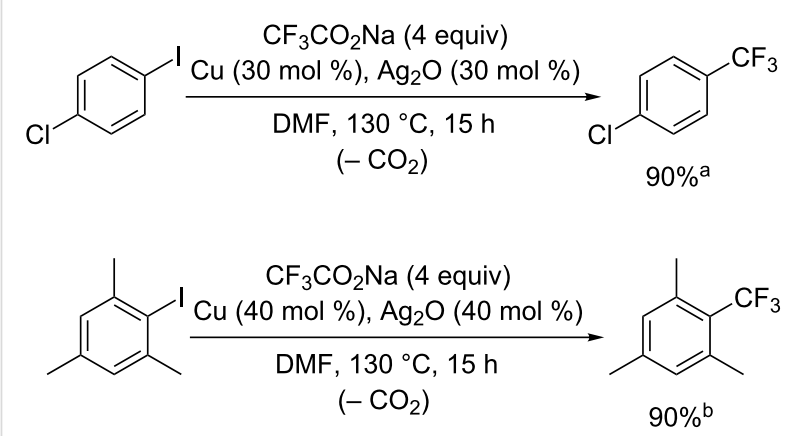

Scheme 5: Trifluoromethylation of aryl iodides with small amounts of

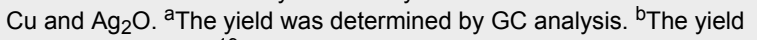
was determined by ${ }^{19} \mathrm{~F}$ NMR analysis using $\mathrm{CF}_{3} \mathrm{CH}_{2} \mathrm{OH}$ as an internal standard.

\section{Trifluoromethylation with difluorocarbene and} fluoride ions

The reaction system with $\mathrm{ClCF}_{2} \mathrm{CO}_{2} \mathrm{Me} / \mathrm{KF} / \mathrm{CuI}$ also generates $\mathrm{CF}_{3} \mathrm{Cu}$ in situ [40,41] (Scheme 7). The demethylation of $\mathrm{ClCF}_{2} \mathrm{CO}_{2} \mathrm{Me}$ proceeds by iodide, followed by decarboxylation of the resulting chlorodifluoroacetate to provide difluorocarbene (: $\left.\mathrm{CF}_{2}\right)$, trapped by fluoride to give the $\mathrm{CF}_{3}{ }^{-}$species. This reacts with $\mathrm{CuI}$ leading to $\mathrm{CF}_{3} \mathrm{Cu}$.

The method described above for the trifluoromethylation of aryl iodides with $\mathrm{ClCF}_{2} \mathrm{CO}_{2} \mathrm{Me}$ and fluoride can be utilized for clinical studies. Herein, we introduce one example of decarboxylative $\left[{ }^{18} \mathrm{~F}\right]$ trifluoromethylation for positron emission tomography (PET) studies. A synthetic methodology for $\left[{ }^{18} \mathrm{~F}\right]$ labelled- $\mathrm{CF}_{3}$ arenes is desired for the application of PET imaging. The reason is that the $\left[{ }^{18} \mathrm{~F}\right]$ isotope has a longer halflife $(110 \mathrm{~min})$ than ${ }^{13} \mathrm{~N}$ (10 $\left.\mathrm{min}\right)$ or ${ }^{15} \mathrm{O}(2 \mathrm{~min})$; however, the incorporation of $\left[{ }^{18} \mathrm{~F}\right]$ must be rapid and the use of the products containing $\left[{ }^{18} \mathrm{~F}\right]$ must be immediate. Many of the reported strategies have a limited scope of starting materials or require expensive reagents and a multistep synthesis. The $\left[{ }^{18} \mathrm{~F}\right]$ trifluoromethylation performed with commercially available reagents by using $\left[{ }^{18} \mathrm{~F}\right]$ fluoride demands no complex such as 


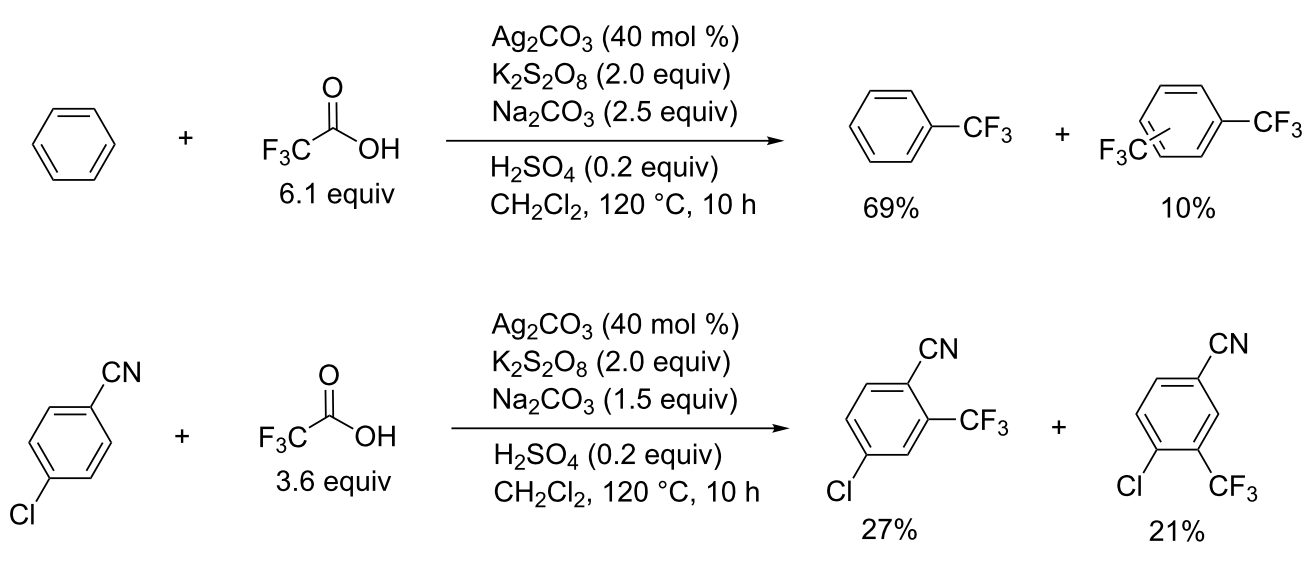

Scheme 6: C-H trifluoromethylation of arenes using trifluoroacetic acid.

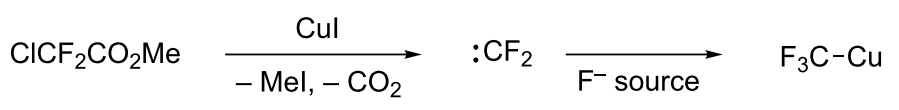

Scheme 7: $\mathrm{CF}_{3} \mathrm{Cu}$ generated from chlorofluoroacetate and Cul.

$\left[{ }^{18} \mathrm{~F}\right] \mathrm{CF}_{2} \mathrm{Cu}$, and thus the method should contribute to efficient PET imaging [42] (Scheme 8).

\section{Synthesis of perfluoroalkylcopper from perfluoroalkyl ketones or esters}

Langlois et al. reported that trifluoromethylation with methyl trifluoroacetate was successfully carried out in DMF or sulfolane at $180{ }^{\circ} \mathrm{C}$ [43] (Scheme 9). Methyl trifluoroacetate, which is more readily available than methyl chlorodifluoroacetate, acts as a trifluoromethylating agent. In this synthesis, the methyl trifluoroacetate/CsF/CuI system would form the tetrahedral intermediates to generate $\mathrm{CF}_{3} \mathrm{Cu}$ species in situ.
Mikami and co-workers accomplished the synthesis of $\mathrm{CF}_{3} \mathrm{Cu}$ at room temperature with perfluoroalkyl ketone derivatives and appropriate nucleophiles. It is indicated that the $\mathrm{CF}_{3} \mathrm{Cu}$ reagent is directly formed from tetrahedral intermediate $\mathbf{A}$ [44] (Scheme 10). The $\mathrm{CF}_{3} \mathrm{Cu}$ reagent was applied to aromatic trifluoromethylation with aryl iodides, which have electron-withdrawing or electron-donating functional groups, in good to high yields (Scheme 11).

The preparation of the $\mathrm{C}_{2} \mathrm{~F}_{5} \mathrm{Cu}$ reagent was investigated as well [45]. Pentafluoropropionate was reacted with $\mathrm{CuCl}$ salt in the presence of $\mathrm{KO} t$ - $\mathrm{Bu}$ to afford $\mathrm{C}_{2} \mathrm{~F}_{5} \mathrm{Cu}$. A variety of aryl bro-
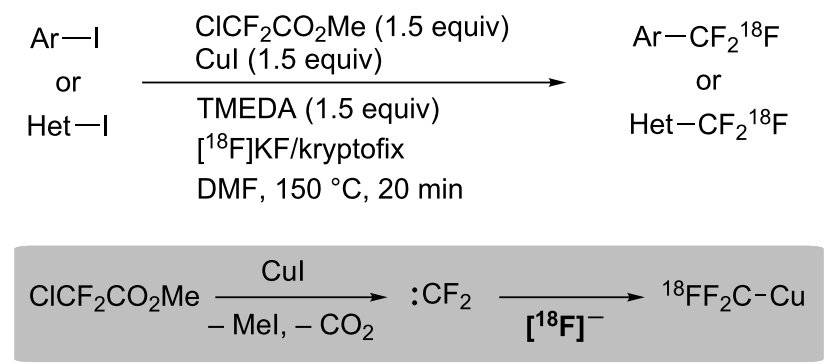

or Het $-\mathrm{CF}_{2}{ }^{18} \mathrm{~F}$
F<smiles>[X]N(C)CCC(Oc1ccc(C(F)(F)F)cc1)c1ccccc1</smiles>

$X=$ Boc, $37 \% \pm 4 \%(n=3)^{a}$

(Eulexin)

Oncology (prostate cancer) 

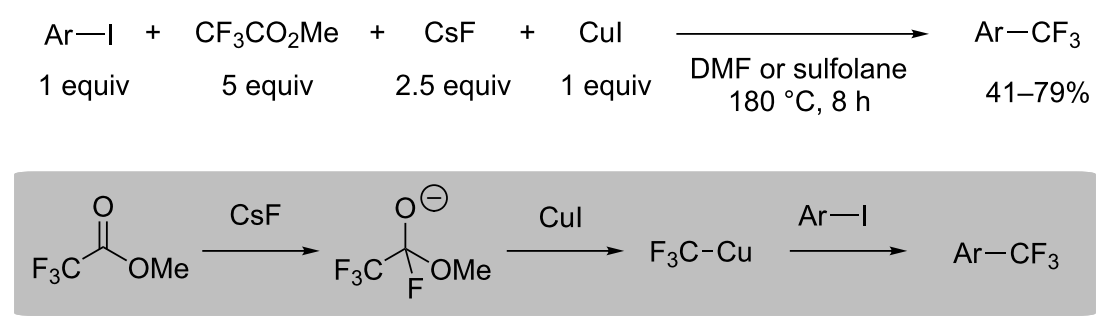

Scheme 9: Trifluoromethylation with trifluoroacetate and copper iodide.

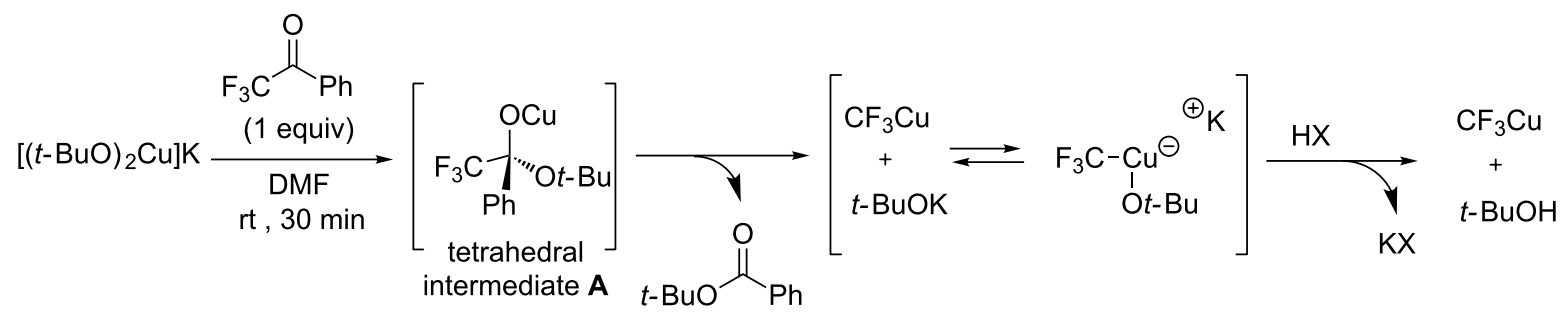

Scheme 10: Preparation of trifluoromethylcopper from trifluoromethyl ketone.

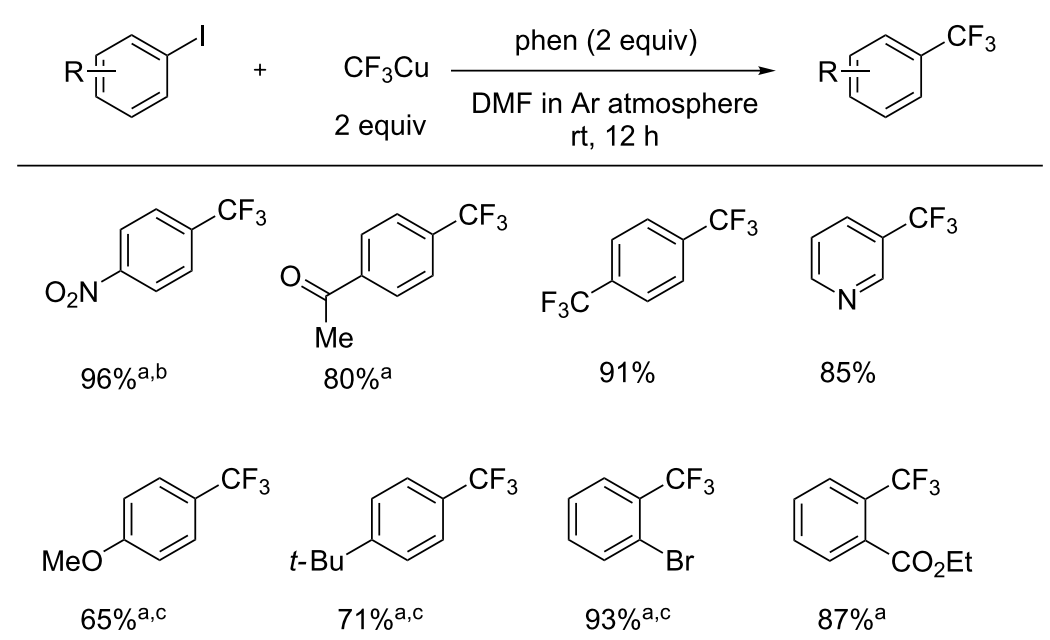<smiles>FC(F)(F)c1cccc2ccccc12</smiles>

$91 \%^{a, c}$<smiles>Cn1cc(C(F)(F)F)c(=O)n([Na])c1=O</smiles>

$78 \% \mathrm{a}, \mathrm{c}$

Scheme 11: Trifluoromethylation of aryl iodides. ${ }^{a}$ /solated yield. ${ }^{b} 1$ equivalent each of $\mathrm{CF}_{3} \mathrm{Cu}$ reagent and 1,10-phenanthroline were used. ${ }^{\mathrm{c}} \mathrm{Reaction}$ temperature was $50^{\circ} \mathrm{C}$

mides were reacted with $\mathrm{C}_{2} \mathrm{~F}_{5} \mathrm{Cu}$ under the optimized conditions, providing pentafluoroethylated aryl products in moderate to high yield (Scheme 12).
The copper-mediated oxidative trifluoromethylation of arylboronic acids are important reactions in organic chemistry because arylboronic acids are widely used. Oxidative, aromatic 


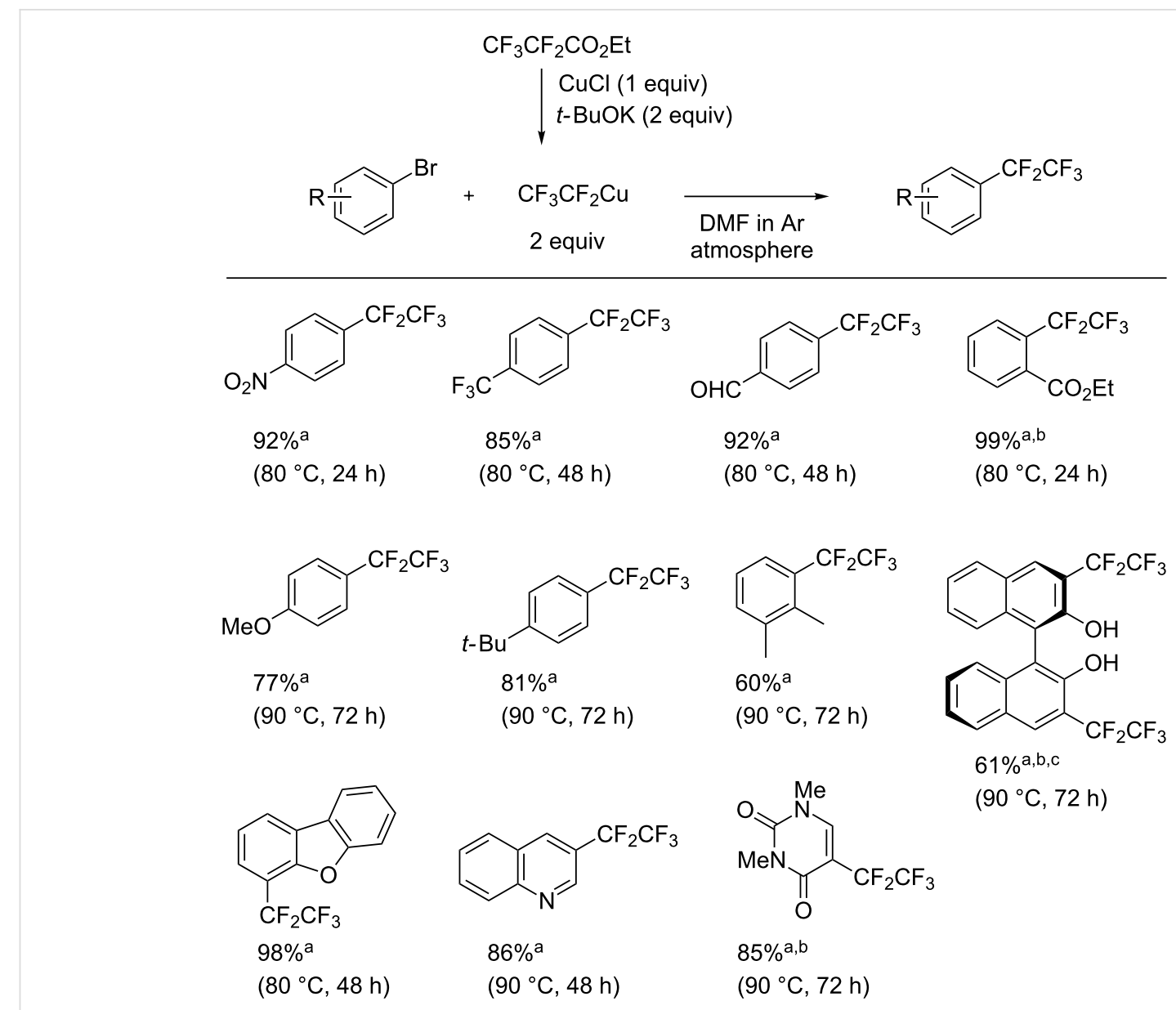

Scheme 12: Pentafluoroethylation of aryl bromides. aYield was determined by ${ }^{19} \mathrm{~F}$ NMR analysis using benzotrifluoride (BTF) or (trifluoromethoxy)benzene as an internal standard. b/solated yield. ${ }^{c} 4$ equivalents of $\mathrm{CF}_{3} \mathrm{CF}_{2} \mathrm{Cu}$ reagent were used.

perfluoroalkylation reactions with arylboronic acid derivatives have been studied by several groups. Qing et al. and Buchwald et al. used the Ruppert-Prakash reagent $\left(\mathrm{CF}_{3}-\mathrm{SiMe}_{3}\right)$ directly as a $\mathrm{CF}_{3}{ }^{-}$source $[46,47]$. From $\mathrm{CF}_{3}-\mathrm{SiMe}_{3}$, Hartwig et al. developed a new combination of Ir-catalyzed $\mathrm{C}-\mathrm{H}$ borylation and oxidative cross-coupling using [(phen $) \mathrm{CF}_{3} \mathrm{Cu}$ ] [48]. Grushin et al. utilized fluoroform for the preparation of $\mathrm{CF}_{3} \mathrm{Cu}$, which participated in cross-coupling reactions with $\mathrm{ArB}(\mathrm{OH})_{2}$ in air [49]. Starting from $\mathrm{CF}_{3} \mathrm{CO}_{2} \mathrm{Et}$ or $\mathrm{C}_{2} \mathrm{~F}_{5} \mathrm{CO}_{2} \mathrm{Et}$, Mikami et al. obtained $\mathrm{CF}_{3} \mathrm{Cu}$ [44] or $\mathrm{C}_{2} \mathrm{~F}_{5} \mathrm{Cu}$ [45]. The substrate scope of trifluoromethylation and pentafluoroethylation suggests that $\mathrm{CF}_{3} \mathrm{Cu}$ and $\mathrm{C}_{2} \mathrm{~F}_{5} \mathrm{Cu}$ reagents are useful $\mathrm{C}_{n} \mathrm{~F}_{2 n+1}{ }^{-}$sources for perfluoroalkylation reactions. Furthermore, $\mathrm{CF}_{3} \mathrm{Cu}$ and $\mathrm{C}_{2} \mathrm{~F}_{5} \mathrm{Cu}$ were utilized for oxidative perfluoroalkylation reactions of arylboronic acids $[44,45]$ (Scheme 13).

\section{Copper-catalyzed group transfer from fluoral derivatives}

Catalytic systems in organic synthesis are desirable from an environmentally benign point of view. With regard to aromatic trifluoromethylation, the effort is devoted to reduce the copper reagents employed in the reactions. Copper-catalyzed aromatic trifluoromethylation with $\mathrm{CF}_{3} \mathrm{SiMe}_{3}$ was developed using phen as a ligand [50]. On the other hand, Billard and Langlois et al. described silylated hemiaminals of fluoral (trifluoroacetaldehyde) that act as a nucleophilic trifluoromethyl source for electrophiles such as aldehydes and ketones [51,52] (Scheme 14).

Amii and co-workers reported a copper-catalyzed aromatic trifluoromethylation from silylated hemiaminals of fluoral [53] (Scheme 15). Hemiaminal derivative $\mathbf{1}$ is readily prepared from commercially available $\mathrm{CF}_{3} \mathrm{CH}(\mathrm{OH})(\mathrm{OEt})$, which is a fluoral equivalent, and morpholine [52].

The substrate scope of the catalytic trifluoromethylation is shown in Scheme 16. Nitro, cyano, and ester groups in iodoarenes were tolerable under the reaction conditions of copper-catalyzed nucleophilic trifluoromethylation. Electronrich iodoarenes underwent the nucleophilic trifluoromethylation to afford the corresponding trifluoromethylated benzenes. 


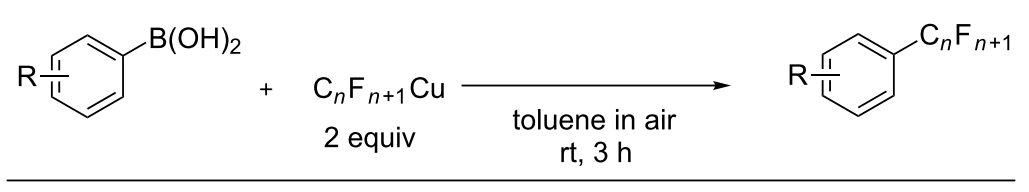<smiles>FC(F)(F)c1ccccc1</smiles>

$96 \%$<smiles>COc1c(C(F)(F)F)cc(C(F)(F)F)c(OC)c1-c1c(OC)c(C(F)(F)F)cc2ccccc12</smiles>

$85 \% \mathrm{a}, \mathrm{b}, \mathrm{c}$<smiles>[R]c1ccc(C(=P)OCc2ccccc2)c([R])c1</smiles>

$\mathrm{R}=\mathrm{F} ; 90 \%$

$\mathrm{R}=\mathrm{CF}_{3} ; 99 \%$

$\mathrm{R}=t-\mathrm{Bu} ; 88 \%$<smiles>FC(F)(F)c1cccnc1</smiles>

$80 \%^{\mathrm{b}}$<smiles>FC(F)(F)c1cccc2ccccc12</smiles>

$90 \%^{\mathrm{a}}$<smiles>Cc1c(C)c2c(c(C)c1OC(=O)c1cncc(C(F)(F)F)c1)CC[C@@](C)(CCCC(C)CCCC(C)CCCC(C)C)O2</smiles>

$57 \%^{a, d}$

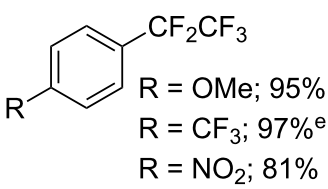

$\mathrm{R}=t-\mathrm{Bu} ; 93 \%$

$\mathrm{R}=\mathrm{CHO} ; 89 \%$

$\mathrm{R}=\mathrm{Br} ; 91 \%$<smiles>FC(F)(F)c1cccc2c1oc1ccccc12</smiles>

$94 \%^{a}$<smiles>FC(F)(F)C(F)(F)c1cnc2ccccc2c1</smiles>

$85 \%$<smiles>FC(F)(F)C(F)(F)c1cccc2c1oc1ccccc12</smiles>

$94 \%$<smiles>Cc1cccc(C(F)(F)C(F)(F)F)c1C</smiles>

$83 \%$<smiles>COc1c(C(F)(F)F)cc2ccccc2c1-c1c(OC)c(C(F)(F)F)cc2ccccc12</smiles>

Scheme 13: Perfluoroalkylation reactions of arylboronic acids. alsolated yield. bDMF was used instead of toluene as a solvent. ${ }^{\mathrm{c}} 4$ equivalents of $\mathrm{C}_{n} \mathrm{~F}_{n+1} \mathrm{Cu}$ reagent were used. ${ }^{\mathrm{d} P i n a c o l b o r o n a t e}$ ester (Bpin) was used instead of boronic acid. eYield was determined by ${ }^{19} \mathrm{~F}$ NMR analysis using BTF as an internal standard.
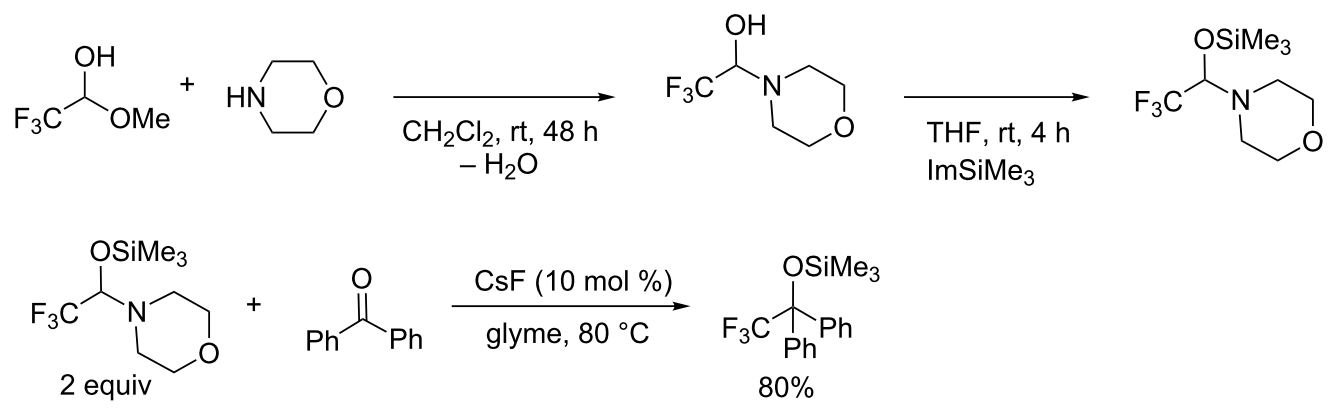


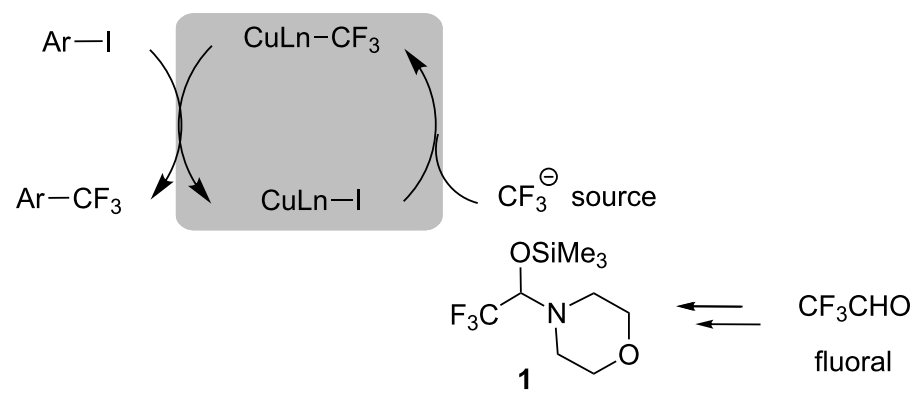

Scheme 15: Catalytic trifluoromethylation with a fluoral derivative.

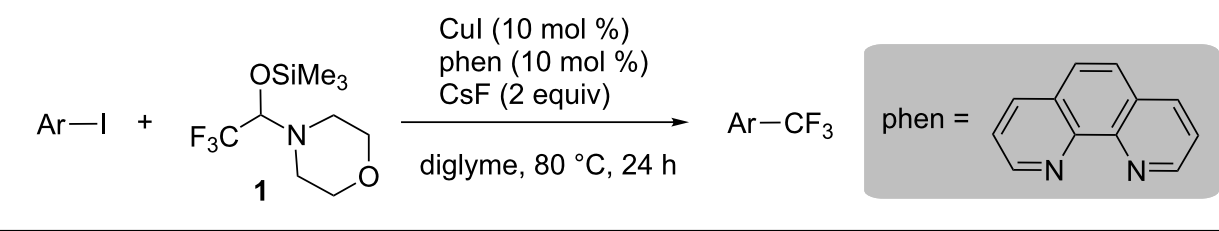

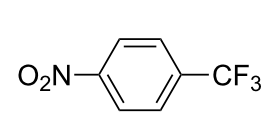

$77 \%$

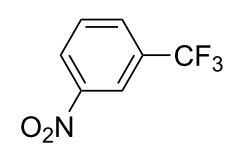

$90 \%$

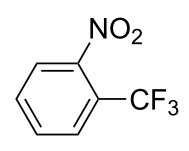

$47 \%$<smiles>N#Cc1ccc(C(F)(F)F)cc1</smiles>

$93 \%$

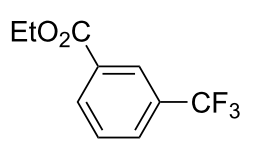

$60 \%$<smiles>FC(F)(F)c1cc(Cl)c(Cl)cc1Cl</smiles><smiles>FC(F)(F)c1ccc(Br)cc1</smiles><smiles>FC(F)(F)c1ccc(-c2ccccc2)cc1</smiles><smiles>O=[W]OC(=O)c1ccc(C(F)(F)F)cc1</smiles><smiles>CCOc1ccc(C(F)(F)F)cc1</smiles>

$97 \%$

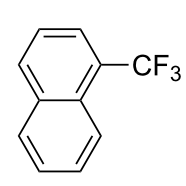

$97 \%$

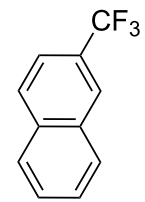

$95 \%$

Scheme 16: The scope of Cu-catalyzed aromatic trifluoromethylation. The yield was determined by ${ }^{19} \mathrm{~F} \mathrm{NMR}$ analysis using (trifluoromethoxy)benzene as an internal standard.

Furthermore, the trifluoromethyl group was introduced into naphthalenes and thiophene with hemiaminal 1.

A catalytic amount of copper was enough to complete the reactions. In the synthesis of trifluoromethylarenes $\left(\mathrm{Ar}-\mathrm{CF}_{3}\right)$, the cross-coupling proceeded via the pathway shown in Scheme 17 [53]. First, the fluoride-ion-induced reaction of hemiaminal 1 with CuI-diamine complex 2 gave copper alkoxide 3 . Then the trifluoromethyl group in $\mathbf{3}$ migrates to generate the trifluoromethylcopper(I) complex 5 with the elimination of $N$-formylmorpholine (4) [54]. Finally, $\mathrm{Ar}-\mathrm{CF}_{3}$ is formed by the coupling of $\mathrm{CF}_{3} \mathrm{Cu}$ complex 5 with $\mathrm{Ar}-\mathrm{I}$, and $\mathrm{CuI}$-diamine complex 2 is regenerated.

\section{Conclusion}

Fluorine has greatly contributed to the advancement of human life and the global demand for organofluorine compounds will continue to increase. Therefore, the introduction of fluorinecontaining functional groups into organic molecules is recognized as a general strategy for the design of drugs and functional materials. In fact, the research activity on selective fluorination and trifluoromethylation has reached a mature state. The progress in fluoroalkylation of organic compounds could be accelerated by the use of fluoroalkylating reagents, which are inexpensive and easy to handle. Perfluoroalkyl carboxylic acid derivatives, such as perfluoroalkyl acetates, trifluoroacetic acid, chlorodifluoroacetates, trifluoromethyl ketones and hemiami- 


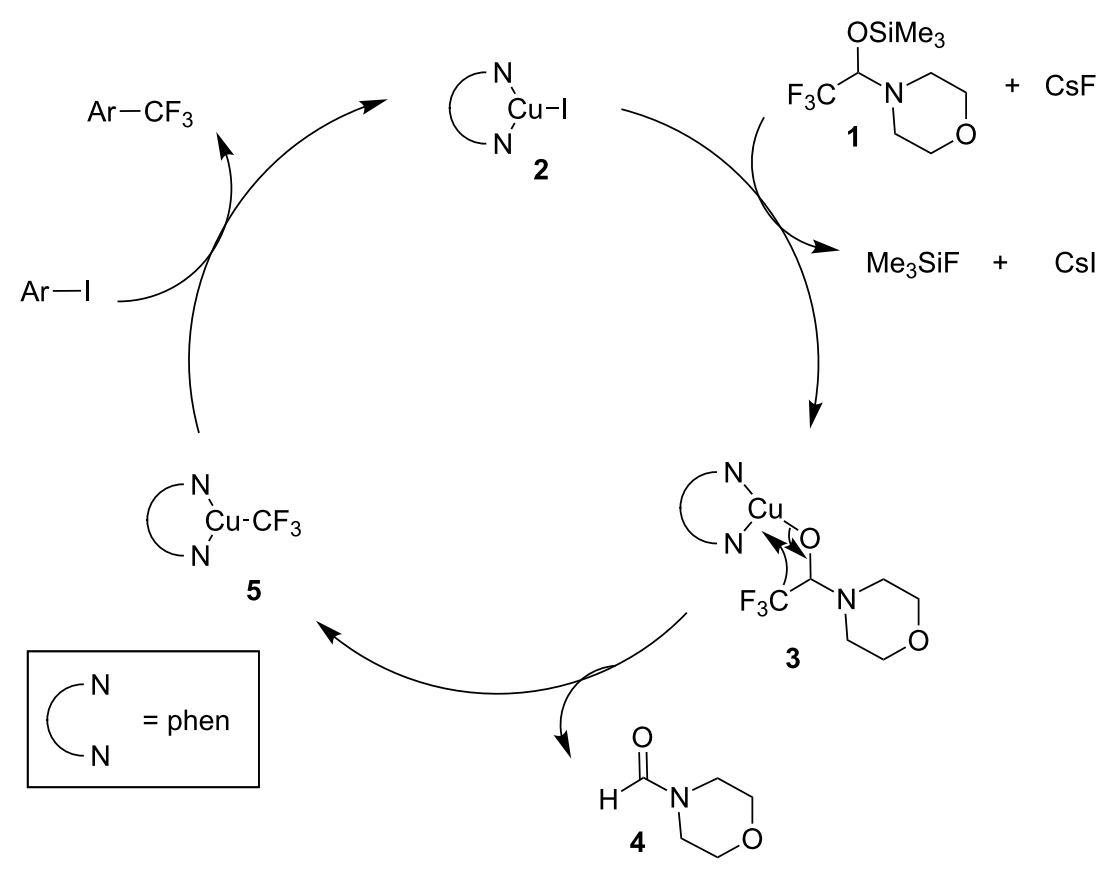

Scheme 17: Plausible mechanism of Cu-catalyzed aromatic trifluoromethylation [53].

nals of trifluoroacetaldehyde, are attractive perfluoroalkyl anion sources for aromatic perfluoroalkylation reactions. The generation of perfluoroalkylcopper from perfluoroalkyl carboxylic acid derivatives via carbon-carbon bond cleavage demands a high reaction temperature or basic conditions. Nevertheless, the simplicity of the operation and the reliability of higher yields would help the synthesis of fluorinated compounds in various fields.

\section{Acknowledgements}

The financial support of the Ministry of Education, Culture, Sports, Science and Technology of Japan and Japan Science and Technology Agency (JST) (ACT-C: Advanced Catalytic Transformation program for Carbon utilization) is acknowledged.

\section{References}

1. Hiyama, T.; Kanie, K.; Kusumoto, T.; Morizawa, Y.; Shimizu, M. Organofluorine Compounds: Chemistry and Application; Springer-Verlag: Berlin, 2000. doi:10.1007/978-3-662-04164-2

2. Kirsch, P. Modern Fluoroorganic Chemistry: Synthesis, Reactivity, Applications; Wiley-VCH: Weinheim, Germany, 2004. doi:10.1002/352760393X

3. Chambers, R. D. Fluorine in Organic Chemistry; Blackwell: Oxford, 2004. doi:10.1002/9781444305371

4. Uneyama, K. Organofluorine Chemistry; Blackwell: Oxford, 2006. doi:10.1002/9780470988589

5. Bégué, J.-P.; Bonnet-Delpon, D. Bioorganic and Medicinal Chemistry of Fluorine; John Wiley \& Sons, Inc.: Hoboken, NJ, 2008. doi:10.1002/9780470281895
6. Ojima, I. Fluorine in Medicinal Chemistry and Chemical Biology; Wiley-Blackwell: Chichester, West Sussex, 2009.

7. Gouverneur, V.; Müller, K. Fluorine in Pharmaceutical and Medicinal Chemistry: From Biophysical Aspects to Clinical Applications; World Scientific Publishing Company: London, 2012. doi:10.1142/p746

8. Wang, J.; Sánchez-Roselló, M.; Aceña, J. L.; del Pozo, C.; Sorochinsky, A. E.; Fustero, S.; Soloshonok, V. A.; Liu, H. Chem. Rev. 2014, 114, 2432-2506. doi:10.1021/cr4002879

9. Lundgren, R. J.; Stradiotto, M. Angew. Chem., Int. Ed. 2010, 49, 9322-9324. doi:10.1002/anie.201004051

10. Furuya, T.; Kamlet, A. S.; Ritter, T. Nature 2011, 473, 470-477. doi:10.1038/nature 10108

11. Roy, S.; Gregg, B. T.; Gribble, G. W.; Le, V.-D.; Roy, S. Tetrahedron 2011, 67, 2161-2195. doi:10.1016/j.tet.2011.01.002

12. Tomashenko, O. A.; Grushin, V. V. Chem. Rev. 2011, 111, 4475-4521. doi:10.1021/cr1004293

13. Besset, T.; Schneider, C.; Cahard, D. Angew. Chem., Int. Ed. 2012, 51, 5048-5050. doi:10.1002/anie.201201012

14. Ye, Y.; Sanford, M. Synlett 2012, 23, 2005-2013. doi:10.1055/s-0032-1316988

15. Wu, X.-F.; Neumann, H.; Beller, M. Chem. - Asian J. 2012, 7, 1744-1745. doi:10.1002/asia.201200211

16. Jin, Z.; Hammond, G. B.; Xu, B. Aldrichimica Acta 2012, 45, 67-83.

17. Studer, A. Angew. Chem., Int. Ed. 2012, 51, 8950-8958. doi:10.1002/anie.201202624

18. Qing, F.-L. Chin. J. Org. Chem. 2012, 32, 815-824. doi:10.6023/cjoc1202021

19. Macé, Y.; Magnier, E. Eur. J. Org. Chem. 2012, 2479-2494. doi:10.1002/ejoc.201101535

20. García-Monforte, M. A.; Martínez-Salvador, S.; Menjón, B. Eur. J. Inorg. Chem. 2012, 4945-4966. doi:10.1002/ejic.201200620

21. Liu, T.; Shen, Q. Eur. J. Org. Chem. 2012, 6679-6687. doi:10.1002/ejoc.201200648 
22. Liu, H.; Gu, Z.; Jiang, X. Adv. Synth. Catal. 2013, 355, 617-626. doi:10.1002/adsc.201200764

23. Liang, T.; Neumann, C. N.; Ritter, T. Angew. Chem., Int. Ed. 2013, 52, 8214-8264. doi:10.1002/anie.201206566

24. Wang, H.; Vicic, D. A. Synlett 2013, 24, 1887-1898. doi:10.1055/s-0033-1339435

25. Browne, D. L. Angew. Chem., Int. Ed. 2014, 53, 1482-1484. doi:10.1002/anie.201308997

26. Zhang, C. Org. Biomol. Chem. 2014, 12, 6580-6589. doi:10.1039/C4OB00671B

27. Sodeoka, M.; Egami, H. Pure Appl. Chem. 2014, 86, 1247-1256. doi:10.1515/pac-2013-1202

28. Xu, J.; Liu, X.; Fu, Y. Tetrahedron Lett. 2014, 55, 585-594. doi:10.1016/j.tetlet.2013.11.108

29. Charpentier, J.; Früh, N.; Togni, A. Chem. Rev. 2015, 115, 650-682. doi:10.1021/cr500223h

30. Liu, X.; Xu, C.; Wang, M.; Liu, Q. Chem. Rev. 2015, 115, 683-730. doi:10.1021/cr400473a

31. Ni, C.; Hu, M.; Hu, J. Chem. Rev. 2015, 115, 765-825. doi:10.1021/cr5002386

32. Alonso, C.; Martinez de Marigorta, E.; Rubiales, G.; Palacios, F. Chem. Rev. 2015, 115, 1847-1935. doi:10.1021/cr500368h

33. Matsui, K.; Tobita, R.; Ando, M.; K., K. Chem. Lett. 1981, 10, 1719-1720. doi:10.1246/cl.1981.1719

34. Carr, G. E.; Chambers, R. D.; Holmes, T. F.; Parker, D. G. J. Chem. Soc., Perkin Trans. 1 1988, 921-926. doi:10.1039/p19880000921

35. Nakamura, Y.; Uneyama, K. J. Org. Chem. 2007, 72, 5894-5897. doi:10.1021/jo070721h

36. Chen, M.; Buchwald, S. L. Angew. Chem., Int. Ed. 2013, 52, 11628-11631. doi:10.1002/anie.201306094

37. McReynolds, K. A.; Lewis, R. S.; Ackerman, L. K. G.; Dubinina, G. G.; Brennessel, W. W.; Vicic, D. A. J. Fluorine Chem. 2010, 131, 1108-1112. doi:10.1016/j.jfluchem.2010.04.005

38. Li, Y.; Chen, T.; Wang, H.; Zhang, R.; Jin, K.; Wang, X.; Duan, C. Synlett 2011, 1713-1716. doi:10.1055/s-0030-1260930

39. Shi, G.; Shao, C.; Pan, S.; Yu, J.; Zhang, Y. Org. Lett. 2015, 17, 38-41. doi:10.1021/ol503189j

40. MacNeil, J. G., Jr.; Burton, D. J. J. Fluorine Chem. 1991, 55, 225-227. doi:10.1016/S0022-1139(00)80126-8

41. Su, D.-B.; Duan, J.-X.; Chen, Q.-Y. Tetrahedron Lett. 1991, 32, 7689-7690. doi:10.1016/0040-4039(91)80566-O

42. Huiban, M.; Tredwell, M.; Mizuta, S.; Wan, Z.; Zhang, X.; Collier, T. L.; Gouverneur, V.; Passchier, J. Nat. Chem. 2013, 5, 941-944. doi:10.1038/nchem.1756

43. Langlois, B. R.; Roques, N. J. Fluorine Chem. 2007, 128, 1318-1325. doi:10.1016/j.jfluchem.2007.08.001

44. Serizawa, H.; Aikawa, K.; Mikami, K. Chem. - Eur. J. 2013, 19, 17692-17697. doi:10.1002/chem.201303828

45. Serizawa, H.; Aikawa, K.; Mikami, K. Org. Lett. 2014, 16, 3456-3459. doi:10.1021/ol501332g

46. Chu, L.; Qing, F.-L. Org. Lett. 2010, 12, 5060-5063. doi:10.1021/ol1023135

47. Senecal, T. D.; Parsons, A. T.; Buchwald, S. L. J. Org. Chem. 2011, 76, 1174-1176. doi:10.1021/jo1023377

48. Litvinas, N. D.; Fier, P. S.; Hartwig, J. F. Angew. Chem., Int. Ed. 2012, 51, 536-539. doi:10.1002/anie.201106668

49. Novák, P.; Lishchynskyi, A.; Grushin, V. V. Angew. Chem., Int. Ed. 2012, 51, 7767-7770. doi:10.1002/anie.201201613
50. Oishi, M.; Kondo, H.; Amii, H. Chem. Commun. 2009, 1909-1911. doi:10.1039/b823249k

51. Billard, T.; Bruns, S.; Langlois, B. R. Org. Lett. 2000, 2, 2101-2103. doi:10.1021/ol005987o

52. Billard, T.; Langlois, R. B.; Blond, G. Tetrahedron Lett. 2000, 41, 8777-8780. doi:10.1016/S0040-4039(00)01552-5

53. Kondo, H.; Oishi, M.; Fujiwara, K.; Amii, H. Adv. Synth. Catal. 2011, 353, 1247-1252. doi:10.1002/adsc.201000825

54. Folléas, B.; Marek, I.; Normant, J.-F.; Saint-Jalmes, L. Tetrahedron 2000, 56, 275-283. doi:10.1016/S0040-4020(99)00951-5

\section{License and Terms}

This is an Open Access article under the terms of the Creative Commons Attribution License

(http://creativecommons.org/licenses/by/2.0), which permits unrestricted use, distribution, and reproduction in any medium, provided the original work is properly cited.

The license is subject to the Beilstein Journal of Organic Chemistry terms and conditions:

(http://www.beilstein-journals.org/bjoc)

The definitive version of this article is the electronic one which can be found at: doi:10.3762/bjoc. 11.286 